\title{
Roland Corbisier: nacional-desenvolvimentismo e hegeliano-marxismo no Iseb
}

\author{
Roland Corbisier:
}

national developmentalism and

Hegelian-Marxism at Iseb

\section{cirstiano cəpovilla*}

DOl: https://doi.org/10.4322/principios.2675-6609.2021.162.004

Roland Corbisier (19142005), filósofo brasileiro 


\section{RESUMO}

O artigo resgata a trajetória política e as formulações teóricas do filósofo Roland Corbisier (1914-2005) desde sua iniciação no integralismo em São Paulo, passando por seus estudos do existencialismo filosófico, até sua adesão ao Grupo de Itatiaia, que mais tarde viria dar origem ao Instituto Superior de Estudos Brasileiros (Iseb, I955-1964). Como diretor-executivo do instituto, destaque especial é dado ao percurso filosófico que conduziu seu pensar, do nacional-desenvolvimentismo como oposição ao "estatuto colonial", transitando pelas formulações acerca de uma filosofia nacional e alcançando a filosofia da práxis, o marxismo, como principal vetor da luta anticolonialista e da independência nacional. As contradições desse período levaram ao golpe de 1964, que fechou o Iseb, eliminou as "reformas de base" e cassou seu mandato de deputado federal. No transcurso dos anos 1970 e 1980 fez contribuições singulares ao pensamento dialético, especificamente no desenvolvimento das conjunções lógicas entre o hegelianismo e o marxismo, assim como polemizou com intelectuais acadêmicos sobre o nacionalismo. Concluímos nossa exposição com a adesão de Corbisier ao PCdoB nos anos 1990, como síntese das suas convicções políticas no socialismo, no desenvolvimento do país e na cultura nacional-popular. Sua biografia intelectual e práxis política constituem sinopse paradigmática das transições ocorridas no Brasil e no mundo durante o século XX.

Palavras-chave: Roland Corbisier. Nacional-desenvolvimentismo. Filosofia nacional. Marxismo. Hegelianismo.

\section{ABSTRACT}

The article recovers the political trajectory and theoretical formulations of philosopher Roland Corbisier (1914-2005) from his initiation into integralism in São Paulo, going through his studies of philosophical existentialism, until his participation in the Grupo de Itatiaia, that would later give origin to the Higher Institute of Brazilian Studies (Iseb, 1955-1964). As executive director of the institute, special emphasis is given to the philosophical path that led his thinking of national developmentalism as opposition to the "colonial situation", moving through formulations about a national philosophy and reaching the philosophy of praxis, Marxism, as the main vector of anticolonial struggle and national independence. The contradictions of that period led to the I964 coup, that closed Iseb, eliminated the "basic reforms" and revoked his mandate as federal deputy. In the course of the I970s and I980s, he made unique contributions to dialectical thought, specifically in the development of logical conjunctions between Hegelianism and Marxism. He also arised polemics with academic intellectuals about nationalism. We conclude our presentation speaking about his affiliation in PCdoB in the I990s as a synthesis of its political convictions in socialism, development of the country, and national and popular culture. His intellectual biography and political praxis conform a paradigmatic synopsis of the transitions that took place in Brazil and in the world during the twentieth century.

Keywords: Roland Corbisier. National developmentalism. National philosophy. Marxism. Hegelianism. 


\section{INTRODUÇ̃̃o}

Ao retratar o período de produção intelectual do Instituto Superior de Estudos Brasileiros (Iseb), não podemos deixar passar em branco o resgate da trajetória política e das formulações teóricas do filósofo Roland Cavalcanti de Albuquerque Corbisier (19I4-2005). Isso porque, em que pese o curto espaço de tempo de existência do Iseb (1955-1964), seu arcabouço ideológico sobreviveu ao longo dos anos, principalmente em personalidades que encarnaram seu espírito. Como primeiro diretor-executivo e um dos idealizadores do instituto, o filósofo Roland Corbisier incorporava como poucos as ideias que animavam os debates acerca do desenvolvimentismo nacional. Sua biografia intelectual e práxis política constituem síntese paradigmática das transições ocorridas no Brasil e no mundo durante o século XX.

O tráfego, ao longo da vida, de uma ideologia de direita - integralista, católica e conservadora - para um nacionalismo progressista e anticolonialista, engajado no projeto das reformas estruturais de João Goulart (1919-1976) às vésperas do golpe civil-militar de 1964, até, finalmente, se filiar ao Partido Comunista do Brasil (PCdoB) nos anos 1990, fez com que Corbisier refletisse em sua trajetória pessoal sobre o que se apresentou às nações que buscavam soberania e desenvolvimento na mesma época na qual o sistema capitalista atingia sua fase mais desenvolvida e oligopolizada, a imperialista. Ao transitar do integralismo para o comunismo, do tomismo para o marxismo, sempre mediada pela filosofia e com o fulgor do nacionalismo anticolonial, a biografia desse pensador brasileiro ainda hoje representa os desafios intelectuais e políticos que estão postos aos setores consequentes da esquerda progressista, nacionalista, democrática e desenvolvimentista.

\section{CORBISIER E A FILOSOFIA}

Nascido em uma família tradicional de São Paulo, Cavalcanti de Albuquerque, por parte da mãe, e Corbisier, de origem francesa, por parte do pai, estudou nos colégios que formavam a elite católica e conservadora da época, o Colégio São Luís e o Ginásio São Bento. Cursou o nível superior na clássica Faculdade de Direito do Largo de São Francisco, que era a formadora, junto com a Faculdade de Direito do Recife, da classe política e da elite burocrática da República Velha, vindo a concluir o curso em I936. Foi durante o período da faculdade que conheceu Plínio Salgado (I895-1975) e passou a constituir o movimento integralista. Na época dizia que "a verdade política é o integralismo, a filosófica, o tomismo, e a religiosa, o catolicismo". Mais tarde, em uma entrevista sobre sua participação no integralismo, dizia em tom autocrítico que "era um adolescente de 17 anos, desprevenido, que nada sabia de economia, de sociologia, de política, e mormente filosofia" (CORBISIER,I976, p. 32). Logo o jovem bacharel percebeu que essa aparente solidez da tríade aristocrática - tomismo, integralismo e catolicismo - não resistiria aos graves acontecimentos que se seguiriam no Brasil e no mundo. 
Em 1937 o golpe do Estado Novo jogou na ilegalidade tanto o integralismo como o Partido Comunista, e, em I939, começava a Segunda Guerra Mundial, conflito ao qual o Brasil foi aos poucos aderindo. Nesse turbilhão de acontecimentos, Corbisier abandona o tomismo filosófico e rompe com o integralismo, acusando Plínio Salgado de "decrepitude e perturbação" (CORBISIER, I976, p.38). Passa a adotar a postura existencialista, principalmente a linha francesa de Henri Bergson (I859-I94I) e Jean-Paul Sartre (1905-1980), sendo um dos pioneiros na introdução deste último no Brasil. Em 1942 seu interesse pelo pensamento conceitual o leva a ingressar na Faculdade de Filosofia do Estado de São Paulo. Lá, aprofundou estudos sistematizados sobre as raízes do existencialismo ${ }^{1}$. Nessa época,

Corbisier via no existencialismo a possibilidade de refletir sobre sua própria condição social e econômica. Estava em jogo a valorização de conceitos de cultura e civilização ocidental, além dos valores espirituais, da propriedade privada. A função do intelectual era justamente essa: a de ser um defensor do espírito, de guardião das tradições, colocadas sob perigo por aqueles que considerava "bárbaros": os marxistas, agressores da civilização ocidental — que traziam consigo o ateísmo e o bolchevismo (GOMES, 2017, p. 55).

Mais tarde, na sua autobiografia filosófica, Corbisier dirá que seu pensamento à época representava justamente a aristocracia decadente de cafeicultores e comerciantes paulistas que fora arruinada tanto pela crise econômica de I929 quanto pela revolução política de I930. Uma aristocracia sem poder e capital. O existencialismo seria, por conseguinte, a "cobertura ideológica" para os indivíduos derrotados e arruinados por uma burguesia ascendente, e o progresso técnico e a licenciosidade do liberalismo seriam os causadores da crise e da decadência da cultura ocidental. Em consonância com os pensadores europeus do pós-guerra, a visão aristocrática se refugiava numa interpretação fundamentalmente metafísica da crise originada pelo capitalismo e pela burguesia, apartada e "situada num plano espiritual, no mundo insensível e perfeito das ideias" (GOMES, 2017, p. 56).

Dessa mesma época data o início de sua relação com o também filósofo Vicente Ferreira da Silva (I916-I963), com quem travou debates e formulações acerca da fenomenologia e do pensamento de Heidegger, o que num certo sentido representou a fase de transição do seu pensamento. Em I948 fundou com seus amigos a revista teórica Colégio, e em 1949 começou a escrever uma coluna semanal para O Estado de S. Paulo. Nesse mesmo ano foi um dos fundadores do Instituto Brasileiro de Filosofia (IBF), juntamente com Vicente Ferreira da Silva, Miguel Reale (I9IO-2006), Renato Cirell Czerna (1922-2005), Luis Washington Vita (I92I-I968), Almeida Salles (I9IO-I996) e Heraldo Barbuy (I9I3-I979), entre outros, editando a Revista Brasileira de Filosofia. 


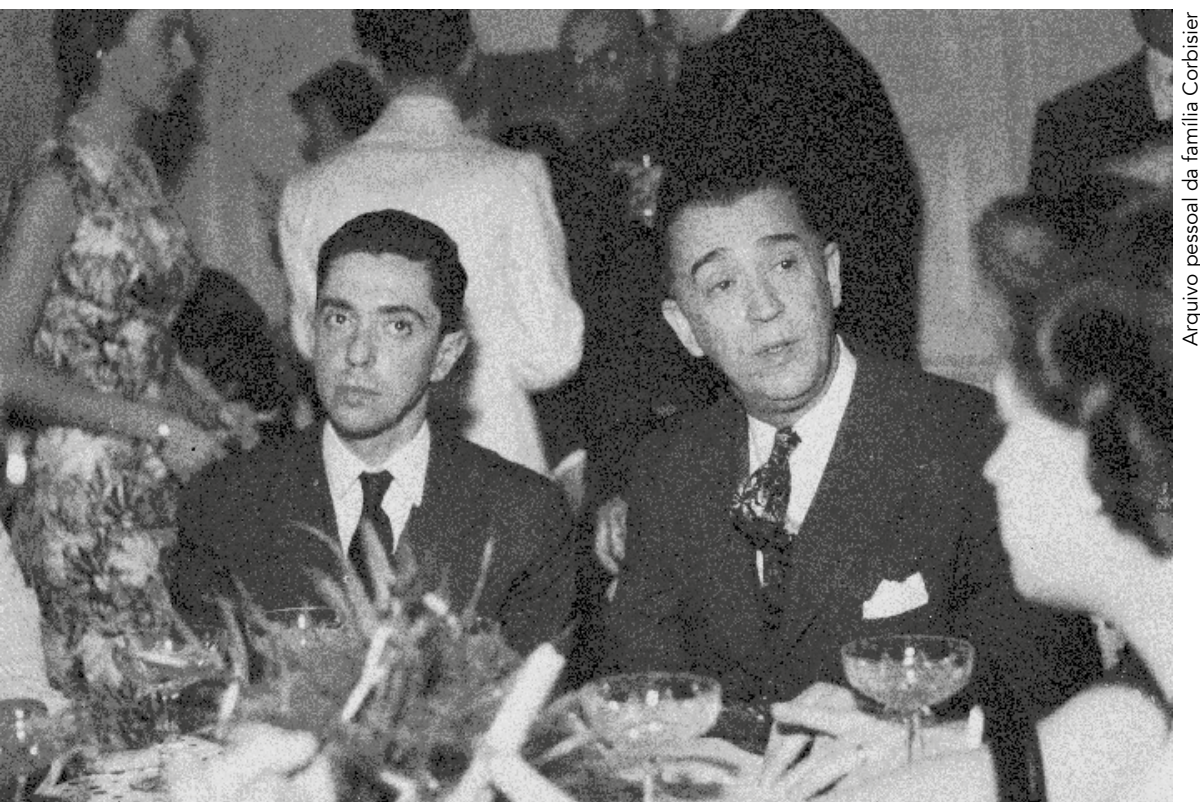

Corbisier ao lado de JK no evento de inauguração do Iseb. Rio de Janeiro (RJ), 1957

\section{DA FILOSOFIA PURA À PRÁXIS TEÓRICA: O CAMINHO ATÉ O ISEB}

Em 1952 foi convidado a integrar o Grupo de Itatiaia, que reunia intelectuais de São Paulo e do Rio de Janeiro para pensar os problemas do Brasil. Vicente Ferreira capitaneava o "grupo paulista" - composto por Almeida Salles, Ângelo Simões de Arruda, Paulo Edmur de Souza Queiroz, José Luiz de Almeida Nogueira Porto e Miguel Reale, além do próprio Roland Corbisier-, ao passo que o "grupo carioca" era formado por Guerreiro Ramos (I9I5-I982), Helio Jaguaribe (I923-20I8), Nelson Werneck Sodré (I9II-I999) e Candido Mendes de Almeida (I928). O choque entre a visão mais cosmopolita e menos afeita aos problemas sociais, característica dos pensadores paulistas, e a perspectiva mais nacional e ocupada com o viés econômico-social, distinção dos intelectuais do Rio de Janeiro, marcará profundamente as escolhas de Corbisier.

O principal articulador do grupo nas reuniões em Itatiaia, Helio Jaguaribe, aglutinava em torno de si as mais variadas personalidades. Entretanto, quando as discussões ultrapassaram a especulação filosófica, incomodados - mormente pelas posições e volúpia intelectual de Jaguaribe, que advogava a aplicação do pensamento à realidade brasileira no sentido da mudança social - , os paulistas (conservadores na maioria) desligaram-se do grupo; só Roland Corbisier permaneceu (BARIANI, 2005, p. 250).

Segundo Roland Corbisier (GOMES, 20I7, p.52), o filósofo Vicente Ferreira da Silva, prócer dos paulistas, deixou a liderança do grupo quando percebeu a impossibilidade de enfrentar intelectualmente Helio Jaguaribe. Tratava-se, no plano teórico, do antagonismo entre a especulação metafísica autocentrada e voltada apenas 
aos discursos absolutos do intelecto e à compreensão profunda da realidade social e política brasileira. Era a divergência entre o modo contemplativo europeu transladado para o país e o conhecimento prático dos problemas brasileiros. O grupo do Rio de Janeiro, então Distrito Federal, detinha maior compreensão histórica e sociológica das questões prementes que envolviam o Brasil nas relações mundiais da divisão internacional do trabalho e do saber. Corbisier percebeu a fragilidade com que o universalismo abstrato dos discursos filosóficos tratava dos temas concretos e que sua autossatisfação cognoscente era apenas subjetiva e se mostrava em disjunção da realidade nacional, que fundamentalmente permanecia estranha aos intelectuais do grupo paulista.

Esse acontecimento foi marcante, pois que completou sua transição filosófica, agora incorporando ao pensamento puro a dura realidade dos problemas brasileiros. Mais tarde irá se afastar do IBF, e em I953, como consequência dos acontecimentos em Itatiaia, incorpora-se ao chamado "grupo carioca", participando da fundação do Instituto Brasileiro de Economia, Sociologia e Política (Ibesp), em que se debatia a questão do petróleo e os rumos do desenvolvimento nacional, passando a editar a revista Cadernos do Nosso Tempo. Inicia a mudança na sua prática política e compreensão teórica, avançava sua transição rumo ao nacionalismo popular.

Em 1954, como desdobramento da sua adesão ao "grupo carioca", vai morar no Rio de Janeiro. Em 955 foi criado, no lugar do Ibesp, o Iseb, órgão do MEC dotado de autonomia administrativa e de liberdade de pesquisa, de opinião e de cátedra, destinado ao estudo, ao ensino e à divulgação das ciências sociais. Corbisier foi escolhido para o cargo de diretor-executivo e também era o responsável pelos cursos de Filosofia, iniciando suas atividades no momento em que Juscelino Kubitschek assumia a Presidência da República, em I956. Além da direção-executiva, o instituto era composto de departamentos, sendo o de Filosofia dirigido por Álvaro Vieira Pinto, o de História, por Nelson Werneck Sodré, o de Política, por Candido Mendes de Almeida, e o de Economia, por Ignácio Rangel. Contava também com um amplo e qualificado conselho, além de colaboradores externos.

O Iseb era uma instituição inédita na vida cultural brasileira, pois tinha por finalidade estabelecer um pensamento prático, desenvolvimentista e modernizador acerca do Brasil, formando uma base intelectual compromissada com projetos nacionalistas sob a alcunha de "nacional-desenvolvimentismo". As elaborações, embora com diversos matizes e abordagens, giravam em torno da compreensão e interpretação do Brasil, com uma clara intenção prática de constituir e assessorar políticas públicas que visassem à emancipação e ao desenvolvimento econômico e cultural da nação. Em outras palavras, o Iseb deveria ser o centro ideológico e estratégico do nacionalismo brasileiro. Uma espécie de ESG (Escola Superior de Guerra), só que civil, com o intuito de desenvolver o país em épocas de paz $^{2}$.

\footnotetext{
Além dos remanescentes do Ibesp, passaram a integrar o núcleo do Iseb: Wanderley Guilherme dos Santos, Ignácio Rangel, Álvaro Vieira Pinto, Carlos Estevam Martins e Antonio Candido. Como colaboradores e conselheiros: Celso Furtado, José Leite Lopes, Tancredo Neves, Guilherme da Silveira, Gilberto Freyre e Heitor Villa-Lobos.
} 


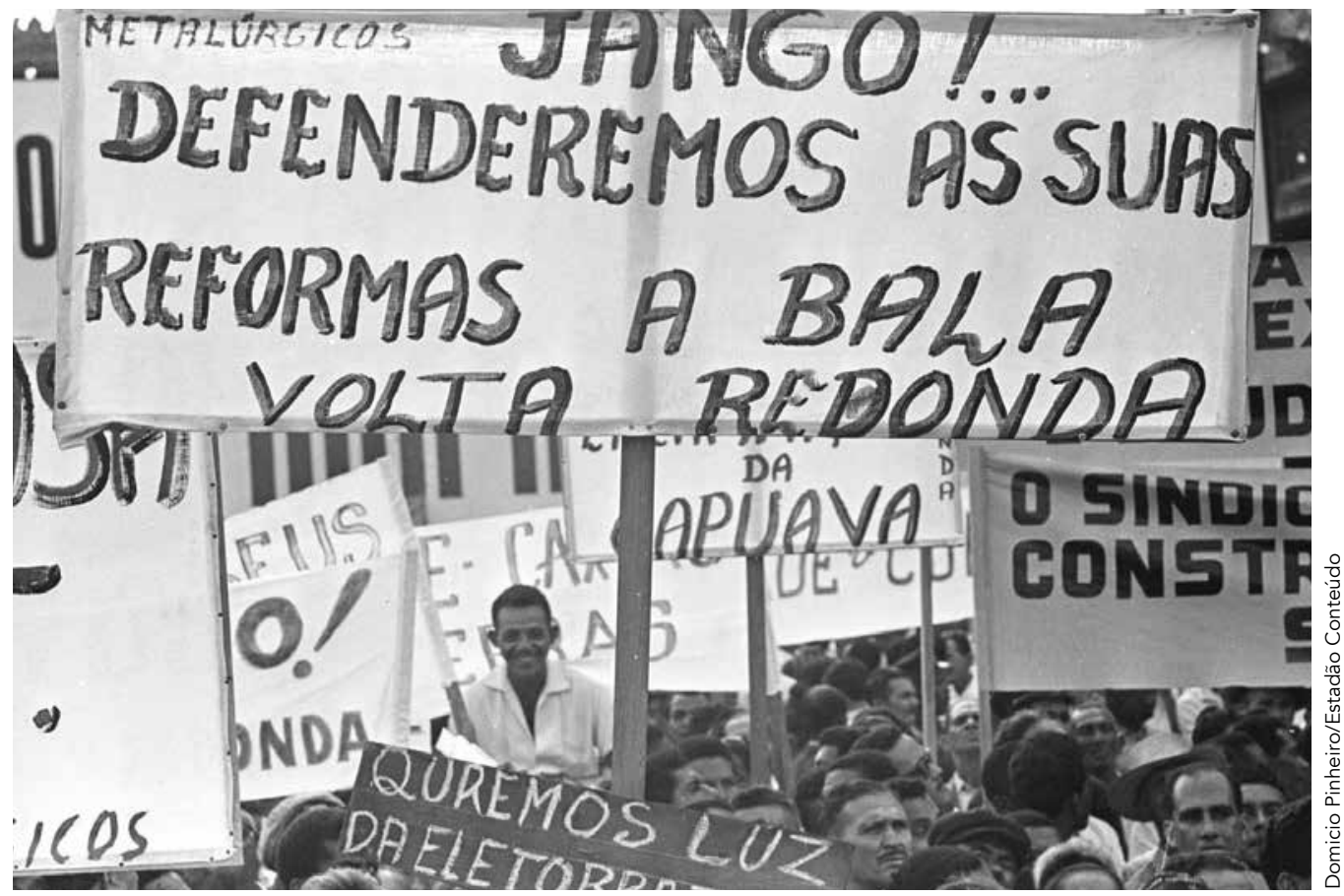

Protesto de rua favorável às reformas de base propostas pelo governo João Goulart

O Iseb foi a oportunidade encontrada para que Corbisier e os demais intelectuais do Grupo de Itatiaia e do Ibesp pudessem concretizar suas ideias. É como se saíssem do plano meramente metafísico e agissem num sentido de intervenção, disseminando um projeto de pensamento nacional-desenvolvimentista para os alunos do instituto. Em outras palavras, o Iseb serviu como metodologia para que aquele grupo de intelectuais colocasse suas ideias no lugar (GOMES, 20I7, p. 84).

Datam dessa quadra as formulações e reflexões acerca da questão nacional e do pensamento filosófico brasileiro. Corbisier encontrou a oportunidade única de realizar a conjunção entre os esforços de sistematizar e institucionalizar o conhecimento filosófico da realidade brasileira e a experiência de um desenvolvimento nacional protagonizado pelo governo JK. Afirmava que o país passava por um processo de descolonização mental e intelectual e que as ciências sociais deveriam se comprometer com as bases desse novo processo. Não caberia neutralidade em um mundo em profundas transformações.

\section{MILITÂNCIA POLÍTICA E O GOLPE DE 1964}

Corbisier sai do Iseb e adentra o campo político-institucional, sendo deputado estadual da Guanabara e, logo depois, em I962, assumindo como deputado federal 
pelo PTB. Sobre essa época de grande polarização política, vale a pena citar interessante passagem:

Em 29 de junho, conforme noticiara $O$ Globo, Corbisier participa de outra manifestação, novamente no Palácio Tiradentes: a inauguração do II Congresso Nacional da Mocidade Trabalhista. Na ocasião, segundo o jornal, o deputado, "em seu discurso, viveu a memória de Lênin, declarando que o PTB deveria ser um partido totalmente esquerdista" (GOMES, 20I7, p. IO6).

Como deputado federal, Corbisier translada para o parlamento suas compreensões sobre os gargalos que entravam o desenvolvimento nacional, passando a defender veementemente as chamadas "reformas de base". Sobre essa época, dirá:

As reformas de estrutura, que se convencionou chamar de reformas de base, tornaram-se o tema dominante da política brasileira, nos dois últimos anos do governo João Goulart, não porque se tivessem convertido no assunto principal dos comícios públicos, da pregação da esquerda, dos editoriais da imprensa ou dos discursos parlamentares, mas por serem exigências ou necessidades objetivas do processo de desenvolvimento deflagrado no país. [...] É, portanto, o agravamento das contradições do desenvolvimento que tornou as reformas de base necessárias e inadiáveis (CORBISIER, 2006, p. I47-I48).

Na compreensão de Corbisier, as reformas de base propostas pelo governo Jango não tinham apenas um aspecto distributivista, nos moldes da social-democracia europeia, mas também a fundamental importância de tocar em questões estruturais, correspondendo às exigências objetivas do processo de desenvolvimento econômico em curso no Brasil. Pela profundidade das mudanças propostas, no contexto do capital monopolista e imperialista, em plena Guerra Fria, as reformas assumiam um caráter de transição revolucionária e anti-imperialista. Percebendo que o momento político entrava em fase decisiva, defendia uma unidade política das forças patrióticas e populares em prol da legalidade, do nacionalismo e das reformas de base. Para ele:

essa união de forças em torno de uma frente única, deveria despir-se de qualquer tipo de liderança personalista, encorajando a tomada de posição, em igualdade de posições, de representantes de todos os grupos e forças que faziam parte da frente popular. Para Corbisier, os objetivos da frente popular deveriam ser: luta contra o golpe de direita e defesa da legalidade, luta contra o processo espoliativo e pela nacionalização da economia brasileira e luta pelas reformas de base (GOMES, 20I7, p.I20).

Na esteira da radicalização da luta de classes veio o golpe de 1964. A experiência do Iseb foi extinta, Corbisier teve o mandato cassado e foi afastado do cargo de professor de Filosofia no ensino secundário e normal do Rio de Janeiro. Em 1965 
foi preso, acusado de ligação com os comunistas. No inquérito policial militar aberto contra o filósofo, consta que o Iseb sob sua direção se constituía em

ativa célula comunista, ligada a tudo o quanto era espúria e ostensivamente desagregador, como a UNE, a Umes, o Caco, entre outros; aos sindicatos marxistas; a Luís Carlos Prestes; a Leonel Brizola; a Sérgio Magalhães; a Osny Duarte Pereira; a José Maria Crispim; a Francisco Julião; a Jacob Gorender; enfim, a tudo quanto neste país tresandava a comunismo e exalava desordem, a ponto de declarar o Iseb "instrumento de luta e de combate" (GOMES, 20I7, p. I25).

\section{FILOSOFIA NACIONAL E COLONIALISMO}

Se fosse possível sintetizar a contribuição de Roland Corbisier ao Iseb - para além dos aspectos institucionais de direção e execução dos projetos - , eu destacaria seu esforço para pautar a luta teórica, filosófica, como uma das formas de trazer à consciência intelectual nacional a dialética entre desenvolvimento econômico e soberania cultural. Os entraves à nossa dependência eram fundamentalmente práticos, caracterizados pela condição do país, de exportador de matéria-prima e de importador da manufatura. Vivíamos numa condição de trabalho servil, na qual as nossas riquezas naturais e o fruto do trabalho dos brasileiros eram drenados para o exterior, não mais empiricamente, como na época da "derrama" colonial, mas através da sofisticada submissão do câmbio pelas poderosas forças do mercado internacional. Ao ditarem os termos em que se processa o intercâmbio, os países desenvolvidos determinam em última instância nossa condição de exportadores de matéria-prima e de consumidores passivos de seus produtos acabados e industrializados, tanto mercadorias materiais quanto artigos espirituais. A miséria e a dependência material se refletem na pobreza e heteronomia espiritual.

Essa realidade infraestrutural brasileira era mantida essencialmente estática desde o período colonial e se refletia nos aspectos culturais e políticos, configurando em seu conjunto as determinações do chamado estatuto colonial. Corbisier avaliava em sua argumentação que, se a questão do subdesenvolvimento nacional encontrava sua contraproposta prática no desenvolvimento, então o problema da superação do estatuto colonial implicava a confecção de um aparato teórico capaz de fazer frente a essa alienação perante a metrópole pensante. A ruptura com a condição de semicolônia em que se encontrava o Brasil implicava, na sua compreensão, não só o desenvolvimento econômico da nossa nação, mas, ao mesmo tempo, uma "conversão do país a ele próprio". Por isso, o esforço no sentido da construção de uma "ideologia ou teoria do desenvolvimento nacional". O desenvolvimento do país era a obra complementar da nossa independência política, ou, dito de outra forma, o país precisava da sua independência econômica e cultural para completar sua independência política. Sobre esse momento, Corbisier nos diz: 

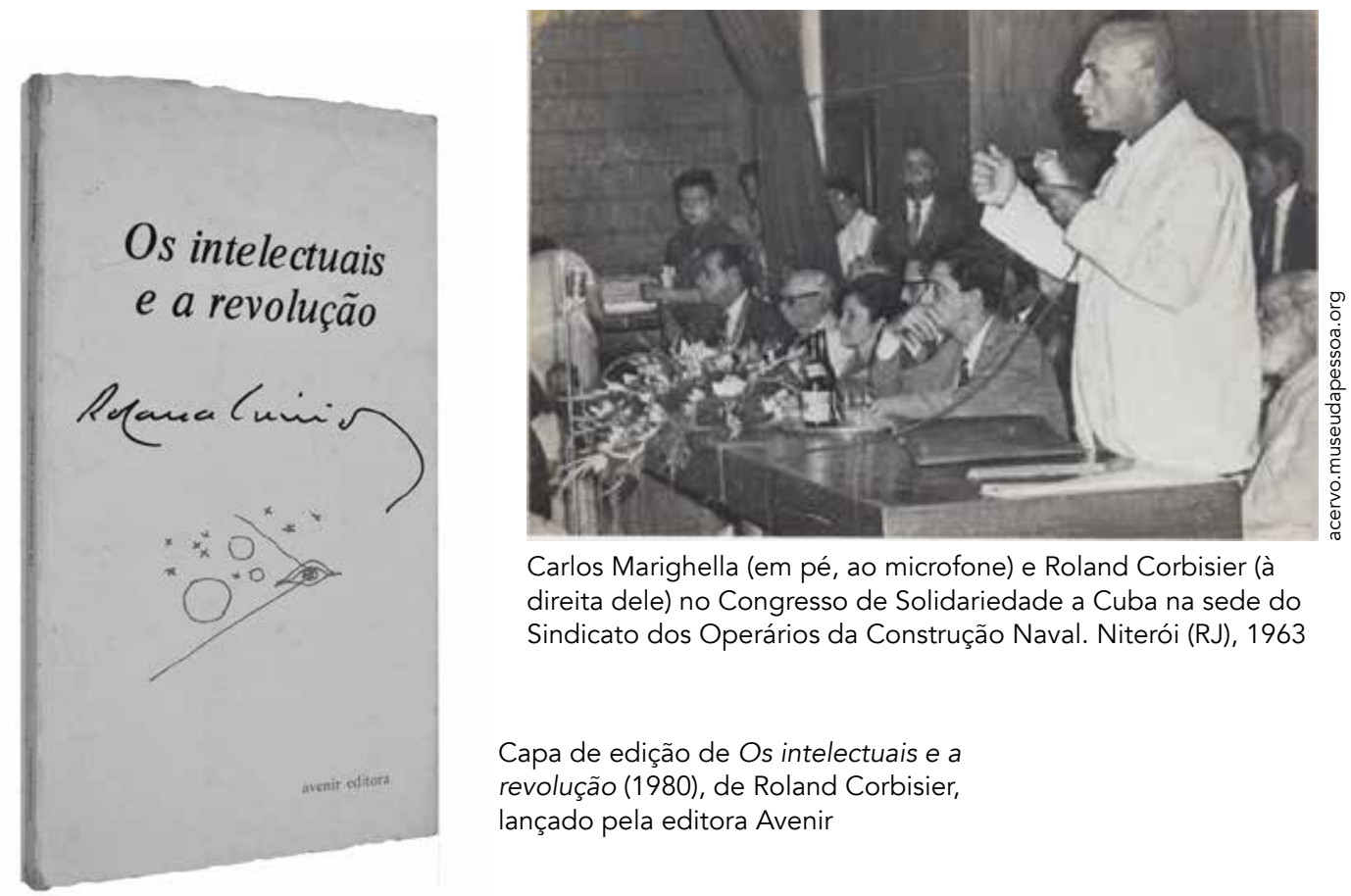

Carlos Marighella (em pé, ao microfone) e Roland Corbisier (à direita dele) no Congresso de Solidariedade a Cuba na sede do Sindicato dos Operários da Construção Naval. Niterói (RJ), 1963

Capa de edição de Os intelectuais e a revolução (1980), de Roland Corbisier, lançado pela editora Avenir

U estatuto colonial não incluía, portanto, apenas a esfera do que se poderia chamar de econômico, mas abrangia, também, o campo do "ideológico", uma vez que, também nesse domínio, exportávamos a imagem da nossa natureza e importávamos a ótica metropolitana, o repertório das ideias que procurava justificar, ou racionalizar, o estatuto da dependência. Não nos víamos com nossos próprios olhos, mas através de uma visão alienante, que convinha aos interesses da metrópole (CORBISIER, 1976, p.I7).

A publicação em I960 do livro Consciência e realidade nacional, do também filósofo e membro do Iseb Álvaro Vieira Pinto, trouxe à tona não o problema da consciência na sua universalidade transcendental, mas o processo de criação de uma consciência crítica em face da realidade nacional. Para ele, "ter consciência de algo real" é diferente de ter "consciência do real como tal". Há que se ter uma conjunção entre

pensamento do existente e simultaneamente pensamento da existência, só assim é que se revela a fonte de consciência da comunidade, pois só nesta forma os aspectos do real são considerados como totalidade [...]. A reflexão cognoscitiva transcende os dados singulares imediatos da realidade para abarcá-la como todo (VIEIRA PINTO, 1960, p. 30).

Tal consciência crítica emergiria da sua forma ingênua e subjetiva ao reconhecer os fatores que delegam ao nosso país a condição de periférico economicamente e culturalmente. Tratava-se de trazer à consciência pensante a relação objetiva e determinante entre a metrópole e a condição colonial. Nessa mesma senda colocou-se Corbisier. No livro Formação e problema da cultura brasileira, de I960, ele aponta uma abertura para o desenvolvimento de uma filosofia nacional. Como destaca Sérgio Castanho, 


\section{Corbisier abriu a possibilidade de novas abordagens acerca da fundamentação de uma filosofia autóctone, na medida em que examina historicamente as relações entre o discurso filosófico e o problema da liberdade e da autodeterminação da comunidade nacional}

Corbisier, na linha de Álvaro Vieira Pinto, chega a propor uma filosofia brasileira, "entendida como autoconsciência da cultura", "como tarefa histórica de libertação e não como exercício acadêmico", uma filosofia que traga "a revelação de nossa própria entidade, de nosso ser como destino" (CASTANHO, 2006, p. 6-7).

Para Corbisier, a cultura brasileira, entendida como "totalidade das manifestações vitais que, em seu conjunto, definem o povo brasileiro", forneceria a matéria-prima original sobre como poderíamos descobrir nossa própria forma de pensar. $\mathrm{O}$ fenômeno cultural envolve os aspectos práticos e teóricos, articulando uma relação dialética e de múltiplas determinações entre os processos sociais, ora como condição, ora como resultado das interações entre o poder político e o econômico. Há uma disputa sobre o sentido da nação. A filosofia, como totalidade das relações entre a natureza e a história, é a tomada de consciência desse processo histórico. Mas essa demanda não poderia ser algo formal, separado da realidade.

Há aqui, na minha interpretação, uma compreensão mais profunda sobre a amplitude do que deveríamos conceber por filosofia e pensamento nacional. Corbisier abriu a possibilidade de novas abordagens acerca da fundamentação de uma filosofia autóctone, na medida em que examina historicamente as relações entre o discurso filosófico e o problema da liberdade e da autodeterminação da comunidade nacional. Os discursos devem sempre pressupor aspectos históricos, sociais e políticos como elementos determinantes do modo de vida e da visão de mundo, sendo o verdadeiro chão ontológico de qualquer pensamento que se quer autônomo.

Contra o universalismo abstrato das formulações filosóficas clássicas, afirmava a concretude da história: 
O campo da cultura, assim como o

político e o econômico, está em disputa

de sentidos que, em última instância, são

fornecidos pela compreensão histórica da

nação. Esse tratamento sobre a maneira

de pensar a filosofia no Brasil foi uma

ruptura nos cenários aristocráticos até

então estabelecidos acerca dessa questão

Essa é, a nosso ver, a grande, se não a principal, conquista do pensamento moderno, da filosofia moderna, a tomada de consciência de que não há uma "natureza humana", pré-fabricada na eternidade, porque o Homem é a história do Homem (CORBISIER, I994, p. 60).

Assim, o Brasil é a história do Brasil. É nela que devemos encontrar o elemento cultural e social específico, autônomo, para construir uma grande nação. É necessário desobstruir os caminhos próprios para o desenvolvimento nacional, superando as conjunturas econômicas, políticas e culturais que nos impõe a condição de semicolônia na divisão internacional do trabalho e do saber.

Temos então um ponto chave de abertura para a compreensão de um pensamento filosófico genuinamente nacional: a constatação de que o pensamento, a linguagem, as práticas, as instituições - em resumo, a nossa história — são determinados pelo nosso modo de vida, a maneira como produzimos nossa própria visão do mundo. Relacionar a questão do discurso filosófico ao problema da liberdade e da autodeterminação da comunidade nacional não seria uma simples aplicação de teorias, mas sim uma determinação do nosso modo de vida e de como enxergamos o mundo, isto é, uma destinação das relações do ser histórico-social.

Tensionando ao máximo a abertura proposta pelo pensamento de Corbisier - segundo a qual a cultura brasileira é a área em que reside a originalidade de um pensamento nacional —, temos um horizonte particularmente fértil para o trabalho de autoconhecimento e autodeterminação acerca da nossa anatomia histórica e social. O campo da cultura, assim como o político e o econômico, está em disputa de sentidos que, em última instância, são fornecidos pela compreensão histórica da nação. Esse tratamento sobre a maneira de pensar a filosofia no Brasil foi uma ruptura nos cenários aristocráticos até então estabelecidos acerca dessa questão. 
É claro que o projeto filosófico de Corbisier não tirou dessa constatação todas as consequências possíveis, não tendo sido, portanto, plenamente finalizado. Muito pelo contrário. O que ele possibilitou, no meu entender, foi uma amplitude de abordagens sobre o assunto. A essa desobstrução de perspectivas, novos problemas devem ser agregados, além da necessidade de melhor fundamentar as diversas objeções que a questão levanta.

\section{O APERFEICQOAMENTO DIALÉTICO}

Já em liberdade, mas sofrendo os efeitos da cassação dos seus direitos políticos, Corbisier fundou em 1967 o Centro de Estudos Brasileiros (CEB), ministrando cursos de Filosofia na Associação Brasileira de Imprensa (ABI). Em 1970, auge do obscurantismo ditatorial, pronunciou uma série de conferências sobre a filosofia de Hegel (I770-I83I), comemorando o segundo centenário de nascimento do filósofo alemão, e publicou nos anos seguintes uma série de artigos sobre o tema. Nesses cursos adotou a estratégia hermenêutica de realçar o realismo dialético por trás da linguagem rebuscada e obscura do filósofo alemão. Tornou-se célebre sua palestra sobre a "dialética do senhor e do escravo", presente na Fenomenologia do espírito, como uma descrição da moderna luta de classes.

Sobre esse "retorno" a Hegel, dizia:

Excluídos compulsoriamente, pelo arbítrio e pela violência, do universal concreto, quer dizer, da vida na cidade e no Estado, vida que era uma síntese de pensamento e de ação, de teoria e de prática, refluímos para o universal abstrato, momento anterior, e já ultrapassado, do processo de luta em que nos achávamos engajados. O retorno, porém, digamos desde logo, não era ingênuo, mas plenamente consciente, e visava apenas consolidar as posições irreversíveis em que nos encontrávamos no momento em que fomos colhidos pelo golpe de Estado (CORBISIER, 1976, p. 195).

A partir de então se dedicou à filosofia como outra face da política. Em 1974 publicou a Enciclopédia filosófica; em I975, Filosofia política e liberdade; e, em I976, Filosofia e crítica radical. Em 1974, continuou ministrando diversos cursos na ABI, na PUC-Rio, na UFRJ e no Sindicato dos Médicos do Rio de Janeiro.

Ao centrar suas formulações nos conceitos de cultura, história, totalidade, ideologia e luta de classes, o filósofo mostrava que tinha superado definitivamente o existencialismo subjetivista e aristocrático para se estribar nas formulações dialéticas e objetivas tanto de Hegel quanto de Marx. Não era o caso de afirmar a inutilidade dos pensamentos existencialista e fenomenológico aos quais dedicara anos de estudo, mas de reconhecer que estes estavam subsumidos na compreensão dialética. "Quando instado a definir sua posição filosófica, não hesitava em se dizer hegeliano-marxista." (CASTANHO, I993, p. 4) De fato, Corbisier, na linha de pensamento aberta por V. I. Lênin (I870-I924) e divulgada no Ocidente por Henri Lefebvre (I9OI-I99I), foi 
um dos pioneiros no Brasil a explorar conceitualmente as linhas de conjunção entre Hegel e Marx.

A questão filosófica girava em torno do problema lógico que fundamentava os discursos tradicionais da filosofia clássica. Sabemos que para Kant, em sua Crítica da razão pura, a lógica transcendental oriunda do entendimento - que tinha por objeto o conhecimento do finito e do condicionado - e a razão - que deveria pensar o infinito e o incondicionado - estão completamente separadas em sua estrutura $a$ priori, cabendo à primeira o conhecimento das ciências positivas, e à segunda apenas a metafísica. Isso quer dizer que a lógica transcendental fornece meramente as condições a priori de cognoscibilidade dos objetos pela experiência possível, cindindo definitivamente a forma, estabelecida pelo sujeito, o "eu penso", e o seu conteúdo, caracterizado pelo objeto "em si mesmo", incognoscível. Essa compreensão estabelecida ainda na aurora da contemporaneidade histórica pelo criticismo kantiano é o que passou a vigorar como lógica formal, estruturante dos discursos das ciências positivas, circunscrita apenas aos ditames do entendimento.

Hegel, em outra vertente interpretativa, considera que as categorias lógicas que atuam no ato do conhecer não podem ser separadas e abandonadas à simples analiticidade formal do entendimento, mas são elas mesmas categorias concretas, unificadas pela atividade imanente da racionalidade especulativa da dialética. Em sua Ciência da lógica, afirma:

Aquilo que se costuma compreender como lógica é considerado inteiramente sem levar em conta o significado metafísico [...]. Pelo contrário, a falta de conteúdo das formas lógicas está apenas no modo como elas são consideradas e tratadas. Na medida em que elas se separam como determinações firmes e não são mantidas juntas em unidade orgânica, elas são formas mortas e o espírito não habita nelas, espírito no qual é a sua unidade concreta que vive (HEGEL, 20I6, p. 50).

Corbisier assimila o deslocamento operado por Hegel da unidade sintética do conhecimento puro a priori para a vida espiritual concreta em suas manifestações objetivas da cultura e da história. O problema lógico e metafísico da filosofia é redimensionado para além da estrutura subjetiva do sujeito transcendental a priori, superando suas cisões intrínsecas, passando a ser concebido numa chave objetiva, isto é, submetendo-se a determinações tanto do pensamento quanto do ser.

Seguindo a conexão intelectiva exposta por Lênin nos Cadernos filosóficos de 1916, compreende que as categorias lógicas devem deixar de expressar somente puras formas abstratas, operacionalmente apartadas e destituídas de conteúdo concreto, passando a constituir a execução qualitativa do conhecer histórico e social objetivo e consolidando a passagem da lógica formal para uma lógica do conteúdo, da analítica do entendimento subjetivo para uma dialética da racionalidade real. A dialética absorve as diretrizes metafísicas e as converte em determinações lógicas, encerrando 
essa antiga tradição filosófica no saber científico ao responder à pergunta kantiana "como é possível a metafísica enquanto ciência?" (KANT, 200I, p. 77). À vista disso, o campo em que se desenvolvia a unidade filosófica entre o hegelianismo e o marxismo era a dialética.

Incorporando essas elaborações teóricas, Corbisier criticava qualquer visão estática da questão nacional como a busca de um "ser nacional" ou de um "caráter nacional" - chamava tais visões de "eleáticas", em referência ao "ser uno e imóvel", segundo a formulação do filósofo pré-socrático Parmênides. Para ele, esses entendimentos, aristocráticos e direitistas, fundamentados numa lógica formal, estavam presos a interpretações substancialistas da identidade do país. Entretanto, a nação não é algo fixo e dado de uma vez por todas ao longo da história, mas um processo, ela não é, mas está sendo. Essa visão dinâmica e dialética da nação, como projeto, critica os estereótipos das elites acerca do país. As formulações filosóficas de Corbisier absorvem em sua elaboração o fato de a burguesia brasileira ter tido medo das reformas e se acovardado com a possibilidade do desenvolvimento autônomo, e por isso ter aceitado o golpe de 1964. A pusilanimidade das elites nacionais as fez se eximirem de responsabilidades com a nação, atrelando nosso destino aos interesses das potências exógenas, cedendo os instrumentos políticos, econômicos e culturais que poderiam ser utilizados para os interesses nacionais.

Castanho nos chama a atenção para que, no livro Formação e problema da cultura brasileira, Corbisier, ao falar do papel dos intelectuais, cita Lênin sem revelar a fonte: "se é verdade, como já se disse, 'que não há movimento revolucionário sem teoria do movimento revolucionário', não haverá desenvolvimento sem a formulação prévia de uma ideologia do desenvolvimento nacional" (CASTANHO, I993, p. 92). Em I980 publica Os intelectuais e a revolução, um livro que foi dedicado a Lênin, "filósofo e político", além de conter epígrafes do próprio Lênin, Hegel e Marx.

\section{UNIVERSALISMO VERSUS PARTICULARISMO}

Na década de 1980, Corbisier continuava ministrando cursos livres de Filosofia que versavam sobre introdução à filosofia, introdução à lógica dialética, filosofia da história, filosofia do direito, introdução histórica ao pensamento político, ideologia e cultura brasileira. Mais tarde, expôs parte desses cursos em uma série de livros intitulados de Introdução à filosofia, publicados pela Civilização Brasileira em sete volumes (o primeiro tomo, em I983; o último, em 2002).

Em 1985 se envolve em uma polêmica pública com a filósofa Marilena Chauí. O episódio foi estampado na capa do Caderno B do Jornal do Brasil com a manchete "Uma polêmica: Chauí x Corbisier", que remetia a uma matéria assinada pelo filósofo e crítico de arte Wilson Coutinho (1947- 2003). Tratava-se das opiniões resultantes do seminário "Tradição/contradição", promovido pela Funarte e que contou com a presença de intelectuais de peso como conferencistas, entre eles, o 
próprio Corbisier, José Américo Pessanha, Marilena Chauí, Alfredo Bosi e Roberto Schwarz.

Corbisier, que na semana anterior tinha palestrado com sucesso sobre o Iseb, fora assistir à palestra de Marilena Chauí cujo título era para ser "A filosofia no Brasil pós-Iseb”. Entretanto, conforme diz a matéria jornalística, Chauí desconsiderou a filosofia produzida no instituto, defendendo a ideia de que uma filosofia do desenvolvimento nacional teria sido um projeto dezenovista, que ainda estava preso ao ideal romântico do Volkgeist (espírito do povo) e ao positivismo de Sílvio Romero (I85I-I9I4). A ideia de que os intelectuais se achavam capazes de ser "guias condutores, pedagogos do povo, doadores de um sentido de consciência nacional inconsciente" constituía um pensamento "autoritário" que ainda não tinha sido "extirpado no Iseb". Para ela, a filosofia deveria ser essencialmente "autônoma" — dando a entender que não deve ter compromissos com a luta pelo poder político nem com a nação. Isso só passou a ocorrer no Brasil de 1965 a 1985, intervalo durante o qual o filósofo se dedicou a "discutir os seus temas e problemas específicos" - tema da palestra de Chauí. Na perspectiva dela, ao filósofo não caberia buscar respostas ou soluções, mas propor indagações (COUTINHO, I985).

Segundo a matéria, Corbisier saiu calado da palestra, mas depois aceitou comentá-la. Para ele, a exposição "foi muito ruim por inúmeros motivos”, tendo sido uma palestra “acadêmica, erudita e pedante". Em sua opinião, faltaria a Chauí uma "concepção revolucionária", que ele via no marxismo. "Passei os olhos sobre um livro dela sobre ideologia, não gostei. Mas ela é muito badalada. É inteligente, mas o Roberto Campos também é. Chauí é pré-marxista, anacrônica e superada”. Sobrou até para o colega de universidade da filósofa, Roberto Schwarz: "ele escreve mal, é confuso e trapalhão. Foi a pior palestra até agora. Chegava a gaguejar.” — disparou Corbisier (COUTINHO, 1985).

A notícia veiculada no Jornal do Brasil reacendeu uma antiga querela que contrapunha pensadores e sociólogos da Universidade de São Paulo ao extinto Iseb. O engajamento político e ideológico dos intelectuais do Iseb em uma agenda de desenvolvimento econômico foi rejeitado por outros intelectuais, principalmente de instituições paulistas, como a USP. Estes repreendiam o Iseb por considerá-lo uma instituição política estatal e, portanto, autoritária, cuja produção carecia de rigor acadêmico em suas formulações. Além disso, viam no engajamento político e institucional e na ideologia nacional-desenvolvimentista do instituto uma distorção da aplicação dos princípios teóricos tanto do liberalismo quanto do marxismo.

Na realidade, quando Chauí destacou o "autoritarismo do Iseb", nada mais fez do que resgatar a antiga crítica das elites paulistas, cristalizadas intelectualmente na USP, contra as reformas modernizantes impostas de cima para baixo pela Revolução de 1930 capitaneada por Getúlio Vargas (I882-I954). Ecoava por trás dessa qualificação o antigo embate político e ideológico entre a aristocracia paulista da República Velha e os desenvolvimentistas e nacionalistas de orientação varguista. O pano de fundo é a própria visão que se tem do Brasil, sob as óticas do cosmopolitismo ou do particularismo. 
Instigante síntese dessa querela histórica é exposta por Christian Lynch quando ele percebe que temos desde a nossa independência política duas maneiras diferentes de pensar o Brasil, expressas no embate entre os "Saquaremas" e os "Luzias":

Saquarema é a denominação dada aos conservadores do Império. Luzia é o apelido dedicado aos liberais da época. Chamavam-se assim por duas razões. Saquarema era o nome do município do Rio onde um dos líderes conservadores, o Visconde de Itaboraí, tinha uma fazenda. Ali o grupo se reunia com frequência. Luzia era uma referência a uma pequena cidade de Minas Gerais, Santa Luzia, onde ocorreu a maior derrota dos liberais nas revoltas de I842 (LYNCH, 2OII, p. 22).

Para Lynch, essas denominações evidenciavam uma disputa entre modelos antagônicos de desenvolvimento nacional: de um lado, o de um Estado centralizado, que pudesse impor sua vontade às províncias; de outro, o de um Estado nacional descentralizado, mero representante dos interesses federativos, garantindo-se a autonomia política dos chefes provincianos. Esse debate permaneceu na República Velha através do federalismo dos governadores, capitaneados principalmente pelo eixo São Paulo-Minas Gerais, centro do pensamento "Luzia". O debate volta à tona quando da vitoriosa Revolução de I930, uma vitória da linha "Saquarema". Com a derrota militar dos paulistas em I932, a elite paulista direciona suas críticas ao autoritarismo getulista.

Anos mais tarde, o debate entre "Saquaremas" e "Luzias" é retomado, agora na forma da oposição sociológica entre Guerreiro Ramos, do Iseb, e Florestan Fernandes, da USP:

O primeiro afirma que há uma tradição nacional a ser seguida; cada país tem a sua. Relativiza a ideia de ciência social e seu universalismo. Lembra que é preciso aproveitar as discussões feitas preteritamente para criar uma ciência social brasileira. Florestan Fernandes pensa o inverso. Diz que é preciso fazer um transplante perfeito das instituições, justamente o plano seguido pela USP. Daí a frase meio debochada dita por Michel Foucault, quando esteve no Brasil, certa época: “A USP é um departamento francês de ultramar." Muita gente achou aquilo um elogio, mas ele quis dizer que a USP era uma cópia de uma universidade francesa de província. Não quero dizer que a USP seja isso, mas transparecem aí essas diferenças de ver o Brasil, fazer o diagnóstico da sociedade brasileira e prescrever os seus remédios (LYNCH, 20II, p. 30-3I).

Para Lynch, essas diferenças históricas e políticas têm seus correspondentes epistemológicos, pois os nacionalistas procuram alterar a realidade do país por meio do conhecimento da realidade nacional, tal qual nossa história nos legou, adaptando às nossas condições as teorias bem-sucedidas em outras nações. O "Saquarema" tem "uma visão mais nacionalista, acha que é menos universalista na proposição dos remédios e sustenta que cada país tem sua tradição, seu jeito de ser" (LYNCH, 2OII, p.3I). Já o pen- 
samento "Luzia", por outro lado, é cosmopolitista, "orientado mais por teorias que vêm de fora, tem menos tolerância com a adaptação e vê nela a corrupção e a deformação". Para evitar a deformação e a corrupção, "convém fazer um transplante perfeito das instituições democráticas liberais estrangeiras" (LYNCH, 2OII, p.30). O pensamento uspiano entende o Brasil com base na categoria do desvio e da deformação.

Hoje a USP é hegemônica, e o cânone intelectualizado produzido por ela também é hegemônico. Mas nos anos 1950 [ess]a universidade não tinha a visibilidade de hoje. Essa visibilidade estava no Iseb. Para se legitimar, o pensamento uspiano buscou criar seu próprio cânone. E quando conseguiu inverter, o Iseb passou a ser visto como a fábrica de ideologia, uma coisa pelega cravada com as mãos do Estado (LYNCH, 20II, p. 36).

O cosmopolitismo filosófico dos paulistas já era conhecido por Corbisier, afinal ele era um dos componentes do "grupo paulista" que se reunia em Itatiaia nos anos 1950. Internamente, do ponto de vista teórico, já tinha superado essa questão. A atividade racional que estabelece mediações entre o particular e o universal não diz respeito a uma aplicação do universal à cultura nacional, mas da concordância interna da cultura da comunidade com o universal. Não se trata, pois, de uma sabedoria contemplativa ou teorética, de uma engenhosidade universal aplicável a casos particulares nem de uma faculdade subjetiva dada a priori e não submetida ao tempo e ao espaço, mas de uma determinação do próprio ser histórico e social. A ação e o domínio da gramática da vida real não são só uma questão de teoria, mas revestem-se de uma ação prática, da participação nas relações e costumes de uma sociedade.

Observando retrospectivamente o debate entre Corbisier e Chaú, Iseb e USP, em torno dos pressupostos da filosofia e das ciências humanas e sociais desenvolvidas no Brasil, defendendo que um pensamento que se quer nacional deve justamente 
argumentar e demonstrar que há conhecimentos, compreensões e práticas na cultura da nossa nação que estão além da jurisdição e da metodologia da ciência social acadêmica estrangeira. Esse encobrimento de relações cognoscentes, históricas e sociais anteriores ou fora do saber acadêmico tradicional não é somente uma questão teórica, mas diz respeito, em grande medida, a uma submissão à legislação epistemológica universalista ${ }^{3}$ que destrói a autoestima de uma legítima inteligência nacional. Adotar tais termos para o pensar filosófico seria aceitar justamente o estatuto colonial. Por isso um pensamento que se quer político e engajado nas questões do país não pode ser universal-abstrato, mas prático-concreto, pois deve materializar nas condições das relações da comunidade nacional os arranjos específicos que constituem nossa própria visão de mundo.

\section{A INCORPORAC̄̃̃ AO PCDOB}

No início dos anos 1990, mais uma vez o filósofo é chamado à baila, desta feita para opinar acerca da queda do chamado "socialismo real" nos países do Leste Europeu. Nessa época, Francis Fukuyama, funcionário do Departamento de Estado estadunidense, vanguarda do nascente neoconservadorismo, publicou artigo que ficou famoso, The end of history, mais tarde transformado em livro com o título The end of history and last man, defendendo a tese de que com a vitória do Ocidente na Guerra Fria a humanidade tinha chegado ao ponto final de sua evolução ideológica, com o triunfo da democracia liberal sobre o fascismo e o comunismo. Vitorioso na Europa e em expansão pela Ásia (Japão, Coreia do Sul, Taiwan), esse regime se estenderia, mais cedo ou mais tarde, a todos os povos civilizados. Essas ideias davam uma medida do debate ideológico daquele período no mundo. Não indiferente a isso, o Brasil refletia esse triunfalismo da vitória definitiva do capitalismo sobre o comunismo, sofrendo a implantação das duras medidas neoliberais do governo Collor (1990-1992). Para muitos, a globalização jogava no museu tanto as ideias comunistas quanto o nacionalismo desenvolvimentista.

No mesmo dia em que o Jornal do Brasil publicava em matéria de capa a reunião do Comitê Central do PCUS que dissolveria a então União Soviética, Corbisier publicou o artigo Tempo de apostasia. Nesse belo e histórico artigo, o filósofo compara aqueles tempos vividos com o episódio da Odisseia, de Homero, em que Ulysses se faz "amarrar ao mastro do navio para não ser arrastado e seduzido pelo canto das

\footnotetext{
Defini legislação epistemológica universalista do seguinte modo: "Assim como o poder político se legitima através de uma legislação jurídica que normaliza as relações entre as classes subalternas e dominantes, constrangendo a luta de classes ao escopo das instituições vigentes, também o domínio metodológico e cientificista dos saberes possui sua própria legislação epistemológica, que procura padronizar suas pretensões de universalidade reprimindo outros pressupostos que atuam sobre o conjunto das compreensões humanas. Essas novas leis do conhecimento se fundamentam no sucesso preditivo das ciências naturais e formais e na pretensão de um deslocamento mecânico dos métodos, ferramentas técnicas, aparatos práticos e linguagens oriundas dessas ciências particulares em direção às humanidades. Haveria, portanto, segundo essa concepção, uma régua objetiva e exógena para mensurar a eficácia dos saberes" (CAPOVILLA, 2020, p. 310).
} 
sereias". Para ele, tratava-se, em termos de metáfora, do "aspecto contraditório da condição humana, que obriga Ulysses a amarrar-se, a prender-se, para libertar-se da sedução, ou da tentação, que o impediria a seguir na viagem e chegar ao porto que pretendia". Então, sentencia o filósofo: "não depende de nós ouvir ou não ouvir o canto das sereias [...], mas, se não podemos evitar que seu canto chegue a nossos ouvidos, de nós depende ceder à sua sedução ou a ela resistir" (CORBISIER, I99I).

Para Corbisier, a crise enfrentada pelos países socialistas existia, de fato. Mas esse seria "um preço histórico que estariam pagando, ao quererem construir o socialismo num mundo ainda dominado pelo capitalismo". Por fim, conclui afirmando:

quanto a nós, permaneceremos amarrados ao mastro das nossas convicções, resistindo ao canto das sereias, certos de que, apesar de todas as crises pelas quais está passando o mundo socialista, o capitalismo não é a última palavra da história. Embora saibamos que o tempo é um tempo de apostasia (CORBISIER, I99I).

Como consequência desse ambiente hostil às ideias marxistas e aos partidos comunistas, o Partido Comunista do Brasil (PCdoB) promovera um seminário na Universidade do Estado do Rio de Janeiro (Uerj) com a presença do seu presidente e histórico militante João Amazonas (1912-2002). O Jornal do Brasil noticiou de forma irônica o encontro, afirmando que, além de militantes do PCdoB, que era o promotor do evento, também "reuniu marxistas ortodoxos do PCB e do PT, alarmados com a dificuldade em defender, junto com as forças hegemônicas de esquerda, a Revolução Russa e o ideário comunista". Entre os "comunistas ortodoxos" estava Roland Corbisier, que na época era filiado ao PT. O filósofo participou do seminário com uma ideia bem clara sobre $\mathrm{o}$ assunto, conforme tinha expresso em artigo no próprio $J B$. $\mathrm{O}$ jornalista responsável pela matéria satirizou a postura do filósofo afirmando que "o mastro do navio de Corbisier era o PCdoB, único partido que adota o marxismo-leninismo" (AZIZ FILHO, 199I).

Logo após, Corbisier filiou-se ao Partido Comunista do Brasil, coerente com sua transição para o socialismo, síntese política do proletariado brasileiro, do desenvolvimento do país e da sua cultura nacional-popular. Em 1994 proferiu uma intervenção no seminário "Rumos da modernidade", também realizado no Rio de Janeiro, e, no mesmo ano, publicou o artigo $O$ Estado, a ética e a política nas páginas da revista Princípios. Corbisier faleceu em 2005 no Rio de Janeiro, aos 90 anos de idade.

\section{CONCLUSÃO}

Termino este pequeno ensaio sobre o Iseb resgatando um pouco da obra e do pensamento do primeiro diretor-executivo do instituto, o filósofo Roland Corbisier. Transcrevo, como conclusão, o que já tinha exposto em ensaio comemorativo aos cem anos do seu nascimento, aqui nas páginas da mesma revista Princípios: 
Nestes tempos de pós-verdade, pós-

modernidade, neoliberalismo e neofascismo,

resgatar o desenvolvimentismo do Iseb e

as formulações nacionalistas do filósofo

Roland Corbisier é manter vivas as ideias

que defendeu - autonomia econômica,

política e cultural do Brasil -, atualizando-as,

debatendo e escolhendo novos rumos

\begin{abstract}
A lembrança tem sempre os motivos da conservação e da renovação. Nestes tempos pelos quais passamos, a exigir sempre um constante consumo de novidades, conservar o acúmulo que adquirimos das gerações passadas, identificando o fio condutor de uma tradição à qual pertencemos, é um aspecto importante da lembrança. Mas trazer ao presente a herança ancestral também é atualizá-la à conjuntura, vivenciá-la. O sentido da lembrança é evidenciar os conteúdos vigentes e novos das palavras-conceitos legadas pela tradição. Conteúdo vivo que nos defronta com questões históricas, políticas e éticas fundamentais, que são a conquista da autonomia da comunidade nacional e a liberdade de escolher e viver seu próprio destino (CAPOVILLA, 20I4, p. 96).
\end{abstract}

Nestes tempos de pós-verdade, pós-modernidade, neoliberalismo e neofascismo, resgatar o desenvolvimentismo do Iseb e as formulações nacionalistas do filósofo Roland Corbisier é manter vivas as ideias que defendeu - autonomia econômica, política e cultural do Brasil - , atualizando-as, debatendo e escolhendo novos rumos. Ganha especial relevo, em minha opinião, um problema suscitado por seus trabalhos e ainda aberto às novas gerações, o da relação entre a questão nacional e o pensamento filosófico.

* Doutorando em Filosofia pela Universidade do Estado do Rio de Janeiro (Uerj). Professor de Filosofia no Colégio Universitário da Universidade Federal do Maranhão (UFMA) e diretor da Fundação Maurício Grabois (Maranhão).

E-mail: capovillacristiano@gmail.com

Texto recebido em 16 de junho de 2021; aprovado em 20 de junho de 2021. 
AZIZ FILHO. Golpe na URSS isola comunistas ortodoxos brasileiros. Jornal do Brasil, Rio de Janeiro, p. 11, 1 set. 1991.

BARIANI. Edison. Uma intelligentsia nacional: Grupo de Itatiaia, Ibesp e os Cadernos de Nosso Tempo. Caderno CRH, Salvador, v. 18, n. 44, p. 249-256, maio-ago. 2005.

CASTANHO, Sérgio. Nasce a nação: Roland Corbisier, o nacionalismo e a teoria da cultura brasileira. 1993. Tese (Doutorado) — Faculdade de Educação, Universidade de Campinas, Campinas, 1993.

. Roland Corbisier: o intelectual da "cultura brasileira". In: CONGRESSO BRASILEIRO DE HISTÓRIA DA EDUCAÇÃO, 4., 2006, Goiânia. Anais... Goiânia: SBHE-UCG, 2006.

CAPOVILLA, Cristiano. Os dispositivos de dominação neocolonial e o ocaso das humanidades. Princípios, v. 39, n. 159, p. 307-320, jul.-out. 2020.

. Roland Corbisier e a abertura para um pensamento nacional autônomo. Princípios, n. 133, p. 96-104, nov.-dez. 2014.

CORBISIER, Roland. Filosofia e crítica radical. São Paulo: Duas Cidades, 1976.

. Introdução à filosofia. Rio de Janeiro: Civilização Brasileira, 1983. t.1.

. Lógica e cronologia das reformas. In: MUNTEAL, Oswaldo; VENTAPANE, Jacqueline; FREIXO, Adriano (Org.). O Brasil de João Goulart: um projeto de nação. Rio de Janeiro: PUC- Rio; Contraponto, 2006. p. 147-173.

O Estado, a ética e a política. Princípios, n. 34, p. 59-67, ago.-out. 1994.

. Tempo de apostasia. Jornal do Brasil, Rio de Janeiro, p. 11, 26 jul. 1991.

COUTINHO, Wilson. Uma polêmica: Chauí x Corbisier. Jornal do Brasil, Rio de Janeiro, p. 1, 11 set. 1985.

GOMES, Fabrício A. Souza. A trajetória intelectual e política de Roland Corbisier. 2017. Tese (Doutorado) - Centro de Pesquisa e Documentação de História Contemporânea do Brasil, Faculdade Getúlio Vargas, Rio de Janeiro, 2017.

HEGEL, Friedrich. A ciência da lógica: 1. A doutrina do ser. Petrópolis; Bragança Paulista: Vozes; Editora Universitária São Francisco, 2016.

KANT, Immanuel. Crítica da razão pura. 5. ed. Lisboa: Calouste Gulbenkian, 2001.

LYNCH, Christian Edward Cyril. Saquaremas e Luzias: a sociologia do desgosto com o Brasil. Insight Inteligência, v. 55, p. 21-37, out.-dez. 2011.

VIEIRA PINTO, Álvaro. Consciência e realidade nacional: a consciência ingênua. Rio de Janeiro: Iseb, 1960. v. 1. 